\title{
Species Selection and Management Under Farmer Managed Natural Regeneration in Dodoma, Tanzania
}

\author{
Eleanor Moore ${ }^{1 * \dagger}$, Tanya van Dijk ${ }^{1+}$, Ayoub Asenga ${ }^{2,3}$, Frans Bongers ${ }^{1}$, \\ Francesco Sambalino ${ }^{4}$, Elmar Veenendaal ${ }^{5}$ and Madelon Lohbeck ${ }^{1,6}$ \\ ${ }^{1}$ Forest Ecology and Forest Management Group, Wageningen University \& Research, Wageningen, Netherlands, \\ 2 Justdiggit, Amsterdam, Netherlands, ${ }^{3}$ LEAD Foundation, Dodoma, Tanzania, ${ }^{4}$ MetaMeta Research, Wageningen, \\ Netherlands, ${ }^{5}$ Plant Ecology and Nature Conservation Group, Wageningen University \& Research, Wageningen, \\ Netherlands, ${ }^{6}$ World Agroforestry (ICRAF), Nairobi, Kenya
}

\section{OPEN ACCESS}

Edited by:

Jess K. Zimmerman,

University of Puerto Rico, Puerto Rico

Reviewed by:

Noel Douglas Preece,

James Cook University, Australia

Bernd Panassiti,

Independent Researcher, Munich,

Germany

*Correspondence:

Eleanor Moore

e.s.moore2@newcastle.ac.uk

${ }^{t}$ These authors have contributed equally to this work and share first authorship

Specialty section:

This article was submitted to

Forest Disturbance,

a section of the journal

Frontiers in Forests and Global

Change

Received: 18 May 2020

Accepted: 30 September 2020

Published: 30 October 2020

Citation

Moore E, van Dijk T, Asenga A,

Bongers $F$, Sambalino $F$

Veenendaal E and Lohbeck M (2020)

Species Selection and Management

Under Farmer Managed Natural

Regeneration in Dodoma, Tanzania.

Front. For. Glob. Change 3:563364.

doi: 10.3389/ffgc.2020.563364
Farmer managed natural regeneration (FMNR) is promoted as a cost-effective technique to restore degraded arable drylands. Evidence comes mainly from the West-African Sahel, where it is a traditional practice, and it is now being promoted across the African continent. In this study, we evaluated the role of the farmer affecting natural regeneration under farmer managed natural regeneration in the highly degraded Dodoma region in Tanzania. We systematically assessed the linkages between species selection, perceived benefits and management practices as reported by 57 farmers in 13 villages involved in FMNR. On average, farmers list 2.8 species to be promoted on their farms as part of the practice of FMNR. In total, a list of 69 species was promoted by the practice, of which most (51) were only mentioned by one or two farmers, indicating that FMNR may contribute substantially to on-farm regional diversity. Most species selected were associated with a range of benefits and the diversity of benefits, not any single benefit, explained species selection under FMNR. Management of FMNR species goes beyond pruning, a practice promoted within FMNR, and is characterized by 10 different practices that are differentially applied to the selected species and individuals. We conclude that species selection and management under FMNR is driven by farmers autonomous decisions, making FMNR both diverse and complex and complicates predicting the extent to which FMNR may successfully contribute to achieving specific restoration outcomes. Monitoring farms over extended periods may increase outcome prediction capacity.

Keywords: farmer-managed natural regeneration, drylands, Tanzania, Africa, farmer, restoration, Dodoma

\section{INTRODUCTION}

Communities worldwide are affected by land degradation, particularly in developing countries, because of high population pressure, reliance on charcoal and woody resources as the main energy sources and livestock overgrazing (Sabogal et al., 2015). Subsistence farmers face decreasing food security resulting from loss of soil quality and declining land productivity (Pimentel and Burgess, 2013). Land degradation not only negatively impacts local livelihoods but also increases the vulnerability of agro-ecosystems to climate change (Webb et al., 2017). Integrated approaches to land restoration can improve livelihoods, enhance biodiversity and increase climate mitigation by 
enhancing carbon sequestration in soil and vegetation (Benayas et al., 2009; Carey, 2020). The long-term success of restoration efforts generally depends on factors such as climate, soil characteristics, availability of materials, disturbance regimes, socio-economic circumstances, and local engagement (Holl et al., 2003; Chazdon, 2008; Crouzeilles et al., 2019). Dryland systems, which include arid, semi-arid and dry-sub humid ecosystems, are particularly vulnerable to land degradation and disturbances (James and Carrick, 2016; Hulvey et al., 2017). Most restoration opportunities for dryland subsistence farming exists in landscapes with moderate to high population pressure (Minnemeyer et al., 2011). Here, integrating trees on farms and grazing land is often a suitable restoration strategy. Research has shown that agroforestry can increase productivity (Schroth and Sinclair, 2003; Glover et al., 2012) and other ecosystem services (Jose, 2009). Agroforestry practices can have a positive impact by controlling pests and diseases, regulating the microclimate and affecting the nitrogen and phosphorus content in the soil (Kuyah et al., 2016; Hoosbeek et al., 2018). In addition, integrating trees can improve household nutrition (Reed et al., 2017) and contribute to both climate change adaptation and mitigation (Roshetko et al., 2007; Zomer et al., 2016). However, planting trees in dryland systems is challenged by low survival rates, in combination with the high costs of planting (Tougiani et al., 2009; Reij and Garrity, 2016; Holl and Brancalion, 2020).

Farmer-managed natural regeneration (FMNR) is considered one of the more promising techniques to restore degraded agricultural landscapes in dryland systems (Weston et al., 2015; Reij and Garrity, 2016). Under FMNR, farmers actively revegetate their fields by nurturing spontaneous/natural woody regeneration, while keeping crop production as their priority (Weston et al., 2015). Farmers make a decision based on what they expect is beneficial for their farmland and which services the woody vegetation provides (Reij and Garrity, 2016). This technique is different from other agroforestry techniques since it does not include the planting of seeds or woody vegetation (Tougiani et al., 2009). As naturally regenerating species are welladapted to local conditions, they have a higher survival rate than planted species in semi-arid regions (Tougiani et al., 2009). FMNR was shown to be effective in agroforestry parklands of Niger, where three million hectares have been revegetated since the 1980s (Rinaudo, 2007). Examples from Niger, more recently also from Burkina Faso, Mali, Senegal, and Ethiopia, show that FMNR can reverse the loss of tree cover and diversity in dryland systems (Garrity et al., 2010), increase crop diversity and raise household income (Haglund et al., 2011; Weston et al., 2015). These examples have led to high expectations toward FMNR as a low cost and effective method for restoration, and it is now being promoted across different regions in Africa, Asia, and the Pacific (Birch et al., 2016). One of the main elements of FMNR is that farmers stay in control over their land and what they grow on it and build on their own past experiences. This is a condition for FMNR to be successful, and at the same time, continued empowerment of farmers is an outcome of the practice (Francis et al., 2015). However, little is known about what farmers select, how they manage natural regeneration and for what reasons.

Different management practices can be applied to select and promote useful woody species, including protection, removal of unwanted plants and soil improvement (Levis et al., 2018). Here the benefits of the woody species and the main purpose of the land will determine the selection and management activities and the extent to which the farmer can promote regeneration. Farmers adapt FMNR to their own needs and have different reasons for their choices (Rinaudo, 2007). Although FMNR is now being scaled out beyond its original range in the Sahel, many unknowns remain regarding the selection and management of natural regeneration by farmers, and how this influences the social and environmental restoration benefits that can be derived from the technique (Chomba et al., 2020). Specifically, there is a lack of studies that allow for a more in-depth understanding of what species farmers promote and manage and for what reasons (but see Ndegwa et al., 2017). Understanding what natural regeneration farmers select and promote is of importance because species differentially affect ecosystem functions, having large consequences for restoration outcomes that can be achieved with FMNR (Lohbeck et al., 2020). To get more insight into these farmer decisions, we consider the role of the farmer based on three pillars that are strongly interlinked and that are expected to eventually determine FMNR outcomes. These three pillars are species selection, perceived species benefits and management practices.

Here we report on the role of the farmer affecting regeneration under FMNR in the Dodoma region in Tanzania. The region has a long history of problems with land degradation, mainly caused by cultivation, overgrazing, cutting down trees for firewood, charcoal and timber and an increasing population (Östberg, 2000). In this region, FMNR has been supported since 2015. We systematically assessed species selection, perceived benefits and management practices by farmers that are involved in the FMNR program. Differences between the districts may also influence the choices farmers make; therefore, we also compared the species that farmers select at the district level. Understanding the role and preferences of the farmer within the practice of FMNR is central to evaluating the success of these projects in the long term, and for improving the implementation of FMNR as a restoration strategy. Specifically, we asked

(1) What species do farmers select under FMNR and is there a difference between the (number of) species selected in each district?

(2) How do the perceived benefits of species influence whether they are selected under FMNR?

(3) What management practices are being applied across species, and how do these reflect their selection and perceived benefits?

\section{MATERIALS AND METHODS}

\section{Study Region}

For this study, we draw from an ongoing project in the Dodoma region in Tanzania where FMNR has been supported on a small scale since 2015 and more widely since 2018. Dodoma is a semi-arid region with an average annual rainfall of 400-570 mm per year (Mayaya et al., 2015). Most households in Dodoma depend on rainfed agriculture (Mayaya et al., 2015) and grow 
cereals (maize, sorghum and millet) and pulses (beans) (Brüssow et al., 2017). Fuelwood is their main energy source (Scheid et al., 2018). The FMNR practice is not considered traditional across these smallholder farming systems.

FMNR is being promoted through the Regreening Dodoma Program, which is jointly implemented by the organizations Justdiggit and LEAD Foundation and started on a larger scale in 2018. Farmers are trained in the practice of FMNR based on four steps which are (1) selecting, (2) pruning, (3) marking, and (4) protecting woody regeneration (see Supplementary Material for detailed project description). No recommendations are given as to which tree species should be promoted; the idea is that the farmer makes his or her own decisions, which is also core to the FMNR practice. Farmers don't receive compensation from the Regreening Program, and participation is on a voluntary base.

Data collection took place in November 2019. We visited 13 villages in six districts and 57 farms across the Dodoma region (Figure 1). One district, Dodoma urban, was not visited since it is not part of the program. All farmers practiced FMNR and were pre-selected randomly based on when they started with FMNR. If the selected farmers were not present at the introduction meeting, other available farmers were randomly selected. For answering the three research questions, we used interviews in which we asked four questions regarding the selection and management of regeneration (1) What species were selected to be promoted under FMNR on the farm? (2) For what reasons did the farmer select each species listed? (3) What management activities did the farmer apply to the species? (4) Why did the farmer perform these management activities? (see Supplementary Material for the interview form). Species were listed using local names, and the corresponding scientific names were derived from floras and online sources which was then cross-referenced with local experts who accompanied us in the field (see Supplementary Table 1 for a list of identified species and references). Full identification was achieved for 46 of the 69 species.

\section{Indicators of Species Characteristics Perceived Species Benefits}

To understand how farmers value the species selected for FMNR, we categorized the mentioned benefits post-data-collection into seven benefits: food, medicinal use, microclimate, products (e.g., timber, hoe handles, beehives), fuelwood, fodder, and soil nutrients (see Supplementary Table 2 for a complete description of each category). The number of mentions of each benefit per species was divided by the number of farmers that listed this species in the interview. This resulted in a species-level score that ranges between zero and one per species for each of the seven benefits. The diversity of benefits per species was calculated by taking the frequency of mentions per service and dividing it by seven (maximum possible score) to come to a score between zero and one. If the score equals zero, no benefits were mentioned for that species, and if the score equals one, all benefits were listed for that species by all farmers.

\section{Species Management Practices}

The farmer listed the management they applied to each species, including if they applied no management. We categorized the management practices post-data-collection into 10 practices: pruning, competition removal, hang iron sheets, fencing, dig a base around the tree, structural support, apply insecticides, watering, marking, and no management (see Supplementary Table 3 for a complete description of each category). No management was included as a category because it is also a conscious management decision taken by farmers. For further analysis, we only included management practices mentioned by more than five farmers. This resulted in four management practices being used; pruning, weeding, fencing and no management applied. Then, for each management practice per species, the count of mentions of each management practice was divided by the number of farmers that listed this species. This resulted in a score between zero and one for each of the 10 management practices per species. The diversity of practices per species was based on all 10 management practices and was calculated by taking the frequency of mentions per service and dividing it by 10 (maximum possible score) to come to a score between zero and one. With a score of zero, the management practice was not applied to that species and with a score of one, the management practice was mentioned by all farmers to be applied to that species.

\section{Statistical Methods}

Statistical analyses were carried out at the species level and only those identified to scientific species names and mentioned by at least three farmers were included. This led to a total frequency of 98 mentions across 18 species. After transformation to improve parametric model fit, we performed an analysis of variance (ANOVA) to understand if there were differences between the numbers of species mentioned by farmers across districts.

We performed a Moran's I test to test for spatial autocorrelation underlying species mentions across the region. This was tested separately for all 18 species with at least three mentions. We found no spatial autocorrelation underlying the abundances of 15 species, the species that did show a spatial pattern in their number of mentions were: Leucaena leucocephala, Senna siamea, and Terminalia sericea. Since most species showed no spatial autocorrelation, we assume independence of our data points.

To evaluate how the perceived benefits affected whether species are favored for FMNR, we used generalized linear models with a Quasi-Poisson distribution. Quasi-Poisson is suitable for non-parametric and over-dispersed count data. Eight separate models were created for each benefit plus the diversity of benefits as the independent variable and the frequency of mentions by farmers as the dependent variable. To understand how management reflects species selection, we also used generalized linear models with a Quasi-Poisson distribution. Five models were created for each management practice plus the diversity of management as the independent variable and the frequency of mentions as the dependent variable. We then correlated species management practices to the perceived benefits using a Kendall distribution to account for non-parametric distributions and small sample size. All statistical analyses were carried out using $\mathrm{R}$ version 3.3.2 ( $\mathrm{R}$ core team, 2014). 

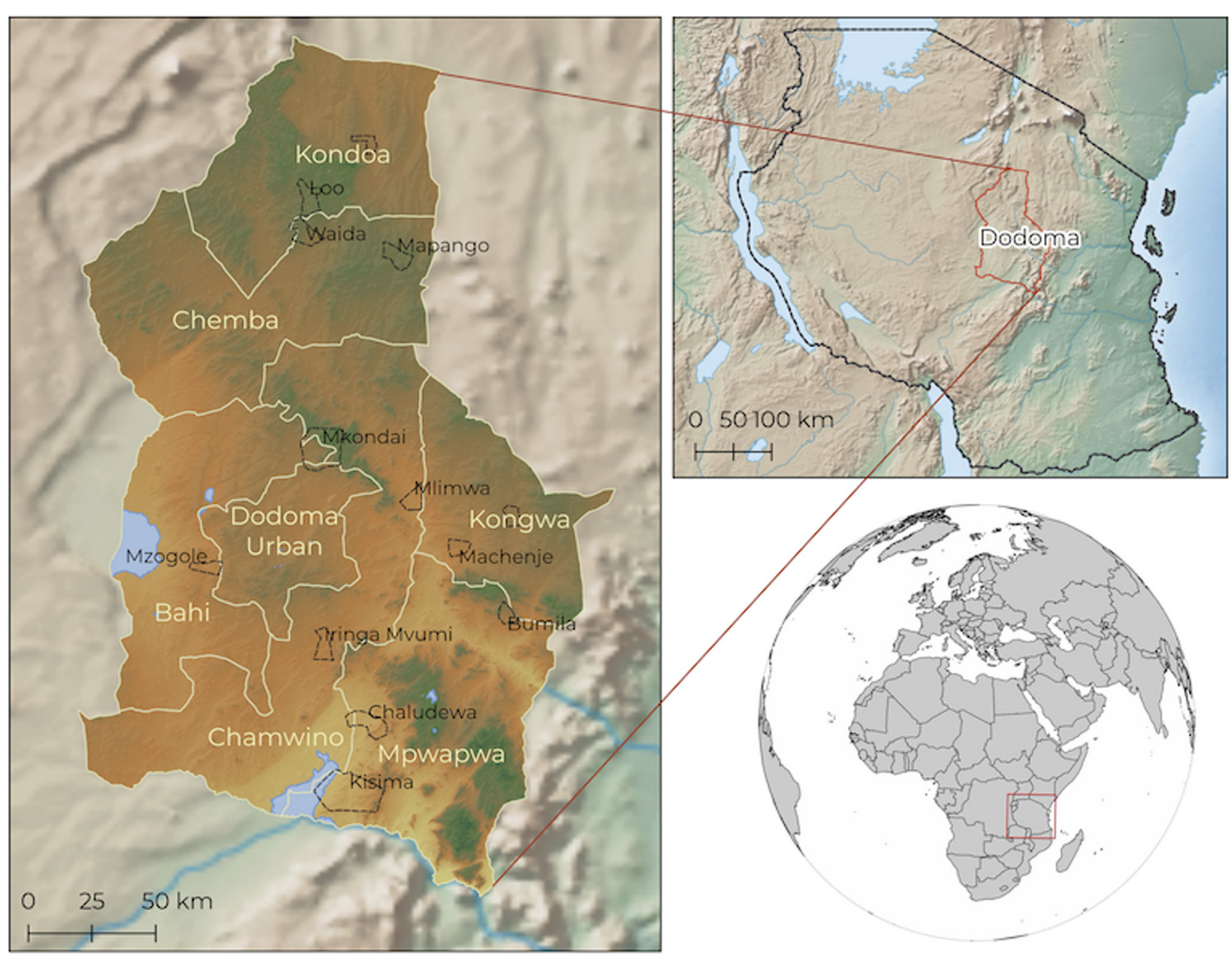

FIGURE 1 | A map of the study region. The districts are written in yellow, and the villages are written in black.

\section{RESULTS}

\section{Species Selection}

A total of 69 species were mentioned to be managed under FMNR, of which 18 species were mentioned three times or more. On average, farmers promoted 2.8 species on their farms. About half of the farmers (52\%) listed that Vachellia tortilis was promoted on the farm as part of FMNR, followed by Dichrostachys cinerea, Senna siamea, Senna singueana $(7 \%)$. There were no significant differences between the number of species mentioned by farmers across districts (Figure 2, $p>0.05, F=0.644, d f=5$ ). Despite this lack of differences, no species were found across all districts. Only $V$. tortilis and $D$. cinerea were found across five of the six districts, and 45 species were only mentioned in one district.

\section{Perceived Species Benefits}

Farmers mentioned 24 different reasons for selecting individuals under FMNR, which we categorized in seven benefits the most common being fuelwood (91\%), products (54\%), and fodder (48\%) (Supplementary Figure 1). Fuelwood was given

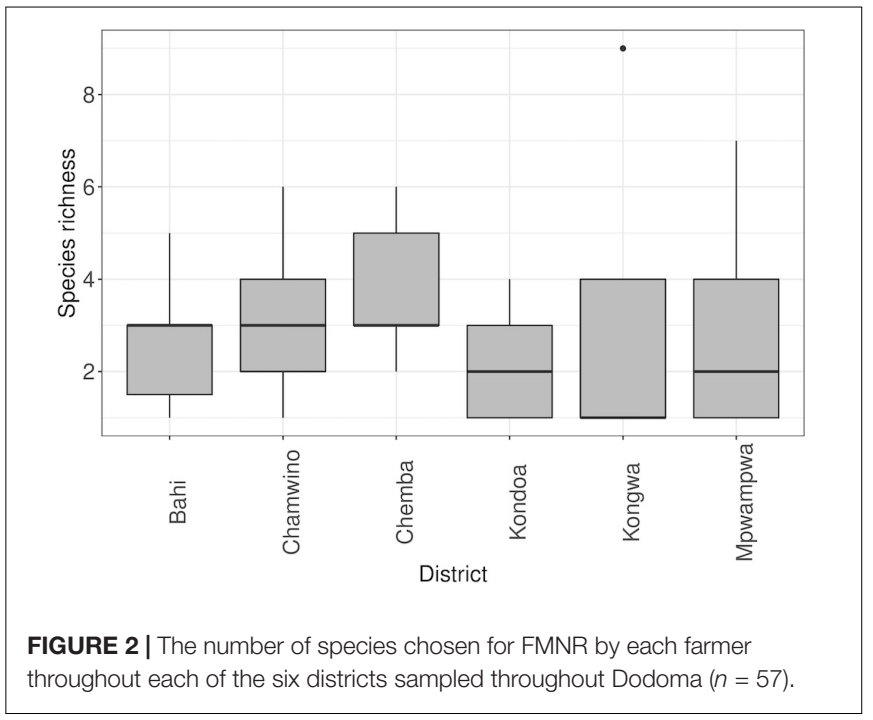

as a reason by at least one farmer for $78 \%$ of species, products $52 \%$, fodder for $42 \%$, soil nutrients for $39 \%$, and food for $30 \%$ of species (Figure 3). The frequency of species 


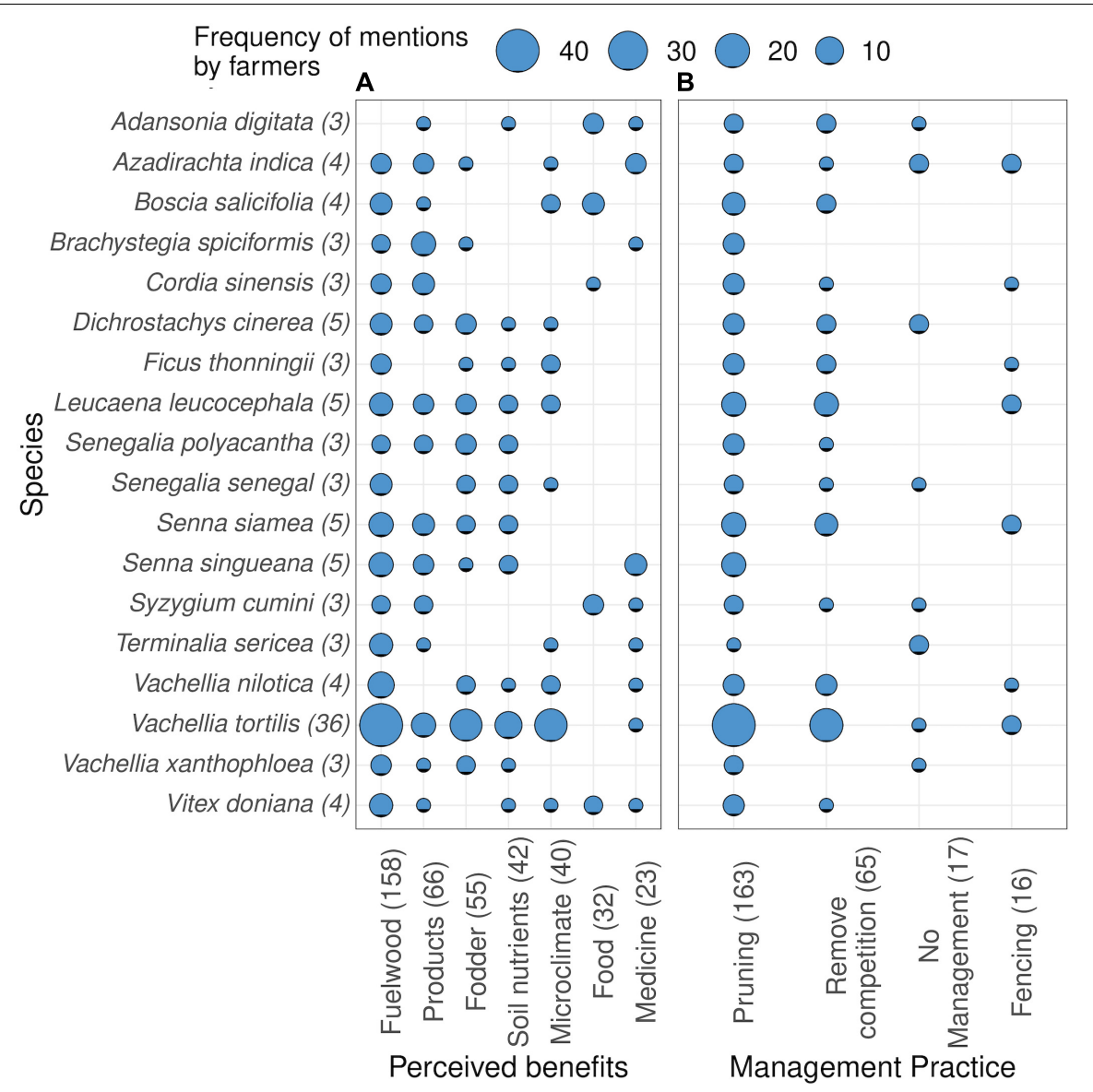

FIGURE 3 | The (A) perceived benefits and (B) management practices by species selected under FMNR as listed by the 57 farmers. The frequency of mentions (max 57) is given by the size of the blue circles. To the right of the species name is the number of mentions for that species (max 57 ). To the right of the perceived benefits and management practices is the total frequency of mentions, these are ordered in decreasing number of mentions. Only 18 species with more than two mentions are shown, see Supplementary Figure $\mathbf{3}$ for all species.

mentions was not explained by any single species benefit. However, species more frequently used for FMNR provided significantly higher diversity of benefits (beta $=5.2, R^{2}=0.5$, $p<0.05)$.

\section{Management Practices}

Pruning was the most important management practice, applied to $90 \%$ of species, followed by competition removal (49\%) (Figure 3). Also "no management" was indicated by farmers and applied to $19 \%$ of the FMNR species followed by fencing, which was applied to $17 \%$ of species. Figure 3 shows the frequency of mentions for management practices by species (see Supplementary Figure $\mathbf{2}$ for the total frequency of mentions, and Supplementary Figure 3 for the frequency of management practices for all listed species). Species more frequently used for FMNR had a significantly higher diversity of management practices applied to them (beta $=4.9, R^{2}=0.48, p<0.05$ ). We found no significant correlations between the management practices applied to species and the perceived benefits (Figure 4, see also Supplementary Table 4).

\section{DISCUSSION}

In this study, we evaluated farmers selection and management of natural regeneration when applying farmer-managed natural regeneration in the highly degraded Dodoma region in Tanzania. Here FMNR has been widely supported and promoted since 2018. We systematically assessed the linkages between species selection, perceived benefits and management practices as reported by farmers that are involved in FMNR. We found that farmers list a total of 69 species to be promoted under FMNR, of which most (51) were only mentioned by one or two farmers, indicating that FMNR may contribute substantially to on-farm regional diversity. Farmers mention a range of benefits associated with species they select, and, although no single benefit could explain what species are selected, the diversity of benefits was associated with species selection. Also, the management of FMNR individuals is characterized by 10 different practices that are differentially applied to the selected species and individuals. We found that the practice of FMNR is complex because of the diversity of reasons to select individuals and because of a wide range of management practices applied. This suggests that 


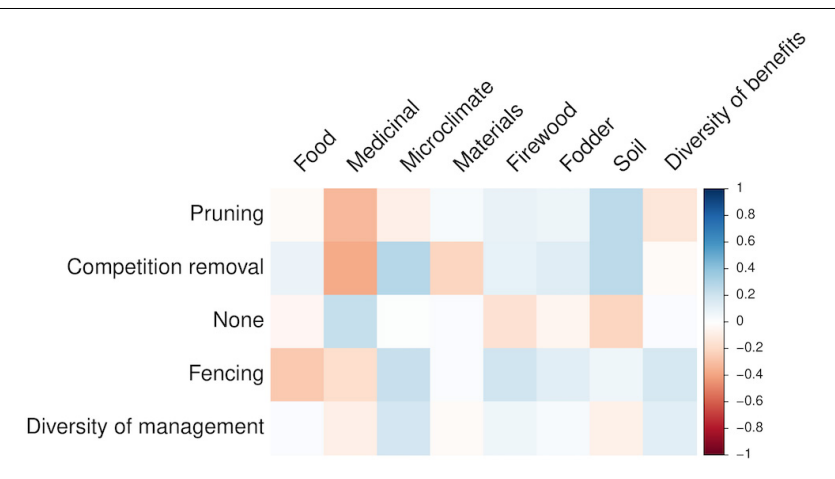

FIGURE 4 | Correlations between management practices (rows) and the species scores for benefits (columns). Reds are negative relations, and blues are positive relations with the darkness of the color indicating the strength of the relation. Asterisks in the cells indicate significant relations ${ }^{\star \star *} p<0.01$, $\left.{ }^{*} p<0.05, N=69\right)$, see also Supplementary Table 4 for test statistics.

FMNR promotes species with multiple benefits and is driven by farmer's autonomous decisions. It is characterized by diversity and complexity, which complicates the potential of predicting restoration outcomes in the long term. Nevertheless, we stress that understanding the role and preferences of the farmer within the practice of FMNR is central to evaluating the success of these projects on the long term, and for improving the implementation of FMNR as a restoration strategy. Further research into the species preferences of farmers may give insight as to how to promote the use of less common species for FMNR, further increasing on-farm biodiversity.

\section{Species Selection Under FMNR}

On average farmers report to promote 2.8 species on their farms. There was no significant difference in the number of species mentioned on the farms across the six districts. 51 out of 69 species were mentioned only once or twice, highlighting the range of different species farmers are selecting for FMNR and supporting findings that FMNR can increase the diversity of woody species on farmland (Haglund et al., 2011). In particular, our result indicates that farmers make very different choices in what species they select and promote, and thereby FMNR may be specifically beneficial for on-farm regional (or gamma) diversity. Increasing biodiversity not only makes systems more resilient but also increases the diversity of resources to the smallholder farmers (Francis et al., 2015).

The species Vachellia tortilis was selected most often by the farmers. Research by Krog et al. (2005) in a nearby region, shows that $V$. tortilis is an important tree for farmers livelihood in Tanzania. In addition, this species is very common in the area (Komwihangilo et al., 1995) and in our study, it was used for FMNR in five of the six districts sampled.

\section{Species Benefits}

Although we found no relation between species selection and any single perceived benefit (Table 1), species more frequently chosen for FMNR provided a higher diversity of benefits. This result highlights that species are valued for a range of different benefits (Figure 3). This is typical for smallholder farming systems where farmers depend on their land for a wide range of services (Ango et al., 2014). Moreover, under FMNR management, the primary purpose of the field remains crop production. Therefore, it may be more suitable for farmers to favor species that provide a wide range of benefits because it reduces the number of species and/or individuals needed in the field, perhaps reducing competition with crops and making it easier for the farmer to manage. This may also explain why we found no relations between any single benefit and species selection. Instead, it is likely that species selection under FMNR may be driven by a more holistic strategy, where the diversity of species is considered at the whole farm level and how these together provide for the different needs of the smallholder farmer.

The species listed most often by farmers, Vachellia tortilis, may be a popular choice for the farmer since it is a common species in the area and provides many benefits: fuelwood, fodder, soil nutrients, microclimate, products and medicine (Figure 3). Species in the Vachellia and Senegalia genera have the ability to fix nitrogen and make it available to other plants in the system (Tedersoo et al., 2018). This can have direct impacts on the productivity of crops. Soil fertility benefits of $\mathrm{N}_{2}$ fixers can be very local, highlighting the need to preserve these in the field with

TABLE 1 | Summary of test results relating (A) the frequency of species mentions to the benefits per species, as tested with regression analyses and (B) the frequency of species mentions to management practices, as tested with regression analyses.

\begin{tabular}{|c|c|c|c|c|c|c|c|}
\hline \multirow{2}{*}{$\begin{array}{l}\text { (A) } \\
\text { Benefits }\end{array}$} & \multirow[b]{2}{*}{ Beta } & \multicolumn{2}{|c|}{ Frequency of mentions } & \multirow{2}{*}{$\frac{(\mathrm{B})}{\text { Management practices }}$} & \multirow[b]{2}{*}{ Beta } & \multicolumn{2}{|c|}{ Frequency of mentions } \\
\hline & & $\mathbf{R}^{2}$ & $p$-value & & & $\mathbf{R}^{2}$ & $p$-value \\
\hline Food & -0.68 & 0.06 & 0.52 & Pruning & 1.22 & 0.06 & 0.466 \\
\hline Medicine & -0.82 & 0.04 & 0.58 & Remove competition & 0.24 & 0.006 & 0.83 \\
\hline Microclimate & 1.65 & 0.15 & 0.19 & No management & -1.22 & 0.07 & 0.47 \\
\hline Materials & -0.8 & 0.07 & 0.44 & Fencing & -0.56 & 0.011 & 0.77 \\
\hline Fuelwood & 1.2 & 0.06 & 0.51 & Diversity of practices & 4.9 & 0.38 & $<0.05$ \\
\hline Fodder & 0.42 & 0.02 & 0.7 & & & & \\
\hline Soil nutrients & 0.06 & 0.00 & 0.97 & & & & \\
\hline Diversity of benefits & 5.2 & 0.5 & $<0.05$ & & & & \\
\hline
\end{tabular}

Given are the beta, $R^{2}$ and $p$-value for each test. 
the crops (Giller and Cadisch, 1995). These results are similar to a study in Kenya where $V$. tortilis as well as a number of other Vachellia and Senegalia spp. (V. gerrardii, Senegalia mellifera, V. nilotica, V. lahai, S. senegal, V. seyal) were also favored under the practice of FMNR and were valued mainly for charcoal, fodder and microclimate (including shade) (Ndegwa et al., 2017).

The majority of species are mainly valued for fuelwood and fodder. The dependency on fuelwood is unsurprising because it is essential for households daily cooking, and there are documented fuelwood shortages in the region (Scheid et al., 2018). Fuel and fodder production were also the main reasons for selecting and managing FMNR trees in Kenya (Ndegwa et al., 2017).

\section{Tree Management}

The first core principle of FMNR as given by Rinaudo et al. (2018) is: "The systematic pruning and management of existing indigenous trees and shrubs by the land user." Pruning, as such, is a core principle and practice to FMNR and other management practices are allowed but not specified. Also, in the Regreening Dodoma program, pruning is identified as a core practice (see detailed project description in Supplementary Materials). This is confirmed by our results: pruning was applied to $90 \%$ of the species selected under FMNR. Pruning is a way to influence the growth form of an individual and can be used to reduce competition for light and water with crops (Jackson et al., 2000). In addition, pruning can increase the light within the crown and affect flower and fruit production (Timmer et al., 1996; Bayala et al., 2008). Pruning is also a consequence of harvesting leaves and branches that can then be applied to the soil as green manure, as mulch, or fed to livestock (Bayala et al., 2012; Cuni-Sanchez et al., 2018). We, therefore, expected that pruning would be associated with the benefits of fodder and soil, which we did not find (Figure 4 and Supplementary Table 4 ).

Interestingly, when farmers are openly asked for management practices, the list is much longer than only pruning; 10 different management practices are given, although some are rarely applied. No management, the deliberate lack of management, was explicitly mentioned. Although under some stricter definition of FMNR this may be excluded, we included it as it is a deliberate decision by some farmers and they see it as part of FMNR. No significant relations between species more frequently used for FMNR and individual management practices were found, although we did find a significant positive relation with the diversity of management practices applied (Table 1). However, this result was strongly influenced by the popularity of $V$. tortilis, and the relation disappeared once this species was removed. This may be because farmers have more knowledge on such a common species to the region (Komwihangilo et al., 1995). In addition, $V$. tortilis is a fast-growing species, which may require the application of several different management practices.

\section{Duration of This Restoration Project and the Need for Long-Term Studies}

Although the diversity of benefits underlies farmers reasons for selecting species, many (51) species were only selected by one or two farmers. This highlights that individual farmers have their own reasons for species selection, and that part of this variation is unpredictable. We expect this may have been caused by the short duration of the FMNR project in Dodoma, which had only started intensively 2 years prior to this study. Probably farmers are still experimenting with the technique and with different species, which over time will show the result of their accumulated experiential knowledge. However, the project in Dodoma has a total duration of only 3-4 years. A recent review highlighted that widespread adoption of FMNR beyond project localities is yet to be evidenced and that the success of these projects depends on intense, long-term external interventions (Chomba et al., 2020). Our results thus highlight the need for long-term studies to monitor the persistence of selected species, and the development of farmers' perceptions and decisions, also beyond project durations. This, to our best knowledge, has not been done yet in studies on FMNR farms and is vital for predicting restoration outcomes in the long term.

\section{Synthesis and Implications for Restoration}

As we are entering the UN decade of ecosystem restoration, there are high expectations for restoration techniques based on natural regeneration as they are considered cheap and effective. Farmer-managed natural regeneration is one such technique. This is to our knowledge among the first studies to systematically assess the role of the farmer in promoting regeneration under FMNR. Regeneration is the basis for the benefits that can be achieved with FMNR as a restoration practice and predicting what can regenerate and where is crucial for predicting its success and thus for restoration planning (e.g., Lohbeck et al., 2020). We found that farmers have a broad knowledge of species and their benefits and promote many different species on the farm. Moreover, FMNR encompasses many different management practices. Species with more diverse benefits were selected more often although many species were only selected by one or two farmers. This highlights that species selection and management under FMNR are driven by farmers autonomous decisions, making it diverse and complicates predicting the extent to which FMNR may successfully contribute to achieving specific restoration outcomes.

\section{DATA AVAILABILITY STATEMENT}

The raw data supporting the conclusions of this article will be made available by the authors, without undue reservation, to any qualified researcher.

\section{ETHICS STATEMENT}

Ethical review and approval was not required for the study on human participants in accordance with the local legislation and institutional requirements. Written informed consent for participation was not required for this study in accordance with the national legislation and the institutional requirements. 


\section{AUTHOR CONTRIBUTIONS}

ML directly contributed through both advice and written work regarding the manuscript. FB, AA, FS, and EV gave valuable feedback as co-authors. All authors contributed to the article and approved the submitted version.

\section{FUNDING}

The Regreening Dodoma Program was funded by the JustDiggIt. EM and TD were supported by the MetaMeta Research. FB was supported by the EU funded LEAP-AGRI (A Long-term EU-Africa Research and Innovation Partnership on Food and Nutrition Security and Sustainable Agriculture) project Roles of Agroforestry in sustainable intensification of small farms and food Security for Societies in West Africa (RAMSES II). ML was

\section{REFERENCES}

Ango, T. G., Börjeson, L., Senbeta, F., and Hylander, K. (2014). Balancing ecosystem services and disservices: smallholder farmers' use and management of forest and trees in an agricultural landscape in southwestern Ethiopia. Ecol. Soc. 19:30. doi: 10.5751/ES-06279-190130

Bayala, J., Ouedraogo, S. J., and Teklehaimanot, Z. (2008). Rejuvenating indigenous trees in agroforestry parkland systems for better fruit production using crown pruning. Agroforest. Syst. 72, 187-194. doi: 10.1007/s10457-007-9099-9

Bayala, J., Sileshi, G., Coe, R., Kalinganire, A., Tchoundjeu, Z., Sinclair, F., et al. (2012). Cereal yield response to conservation agriculture practices in drylands of West Africa: a quantitative synthesis. J. Arid Environ. 78, 13-25. doi: 10. 1016/j.jaridenv.2011.10.011

Benayas, J. M. R., Newton, A. C., Diaz, A., and Bullock, J. M. (2009). Enhancement of biodiversity and ecosystem services by ecological restoration: a meta-analysis. Science 325, 1121-1124. doi: 10.1126/science. 1172460

Birch, J., Weston, P., Rinaudo, T., and Francis, R. (2016). "Releasing the underground forest: case studies and preconditions for human movements that restore land with the farmer-managed natural regeneration (FMNR) method," in Land Restoration, eds I. Chabay, M. Frick, and J. Helgeson (Amsterdam: Elsevier), 183-207. doi: 10.1016/b978-0-12-801231-4.00016-1

Brüssow, K., Faße, A., and Grote, U. (2017). Is sustainable intensification propoor? Evidence from small-scale farmers in rural Tanzania. Resources 6:47. doi: $10.3390 /$ resources 6030047

Carey, J. (2020). News Feature: the best strategy for using trees to improve climate and ecosystems? Go natural. Proc. Natl. Acad. Sci. U.S.A. 117, 4434-4438. doi: 10.1073/pnas.2000425117

Chazdon, R. L. (2008). Beyond deforestation: restoring forests and ecosystem services on degraded lands. Science 320, 1458-1460. doi: 10.1126/science. 1155365

Chomba, S., Sinclair, F., Savadogo, P., Bourne, M., and Lohbeck, M. (2020). Opportunities and constraints for using farmer-managed natural regeneration for land restoration in Sub-Saharan Africa. Frontiers in Forests and Global Change, Section Forest Disturbance

Crouzeilles, R., Santiami, E., Rosa, M., Pugliese, L., Brancalion, P. H., Rodrigues, R. R., et al. (2019). There is hope for achieving ambitious Atlantic Forest restoration commitments. Perspect. Ecol. Conserv. 17, 80-83. doi: 10.1016/j. pecon.2019.04.003

Cuni-Sanchez, A., Pfeifer, M., Marchant, R., Pompeu, P. V., and Burgess, N. D. (2018). Harvesting fodder trees in montane forests in Kenya: species, techniques used and impacts. New For. 49, 511-528. doi: 10.1007/s11056-018-9632-x

Francis, R., Weston, P., and Birch, J. (2015). The Social, Environmental and Economic Benefits of Farmer Managed Natural Regeneration. Australia: Business Communications Consultant.

Garrity, D. P., Akinnifesi, F. K., Ajayi, O. C., Weldesemayat, S. G., Mowo, J. G., Kalinganire, A., et al. (2010). Evergreen Agriculture: a robust approach to supported by research programme ALW (863.15.017), financed by the Netherlands Organisation for Scientific Research (NWO).

\section{ACKNOWLEDGMENTS}

We are grateful to the communities and local officials for their support and for granting permission to collect data on their properties.

\section{SUPPLEMENTARY MATERIAL}

The Supplementary Material for this article can be found online at: https://www.frontiersin.org/articles/10.3389/ffgc.2020. 563364/full\#supplementary-material

sustainable food security in Africa. Food Security 2, 197-214. doi: 10.1007/ s12571-010-0070-7

Giller, K. E., and Cadisch, G. (1995). Future benefits from biological nitrogen fixation: an ecological approach to agriculture. Plant Soil 174, 255-277. doi: 10.1007/978-94-011-0053-3_13

Glover, J. D., Reganold, J. P., and Cox, C. M. (2012). Plant perennials to save Africa's soils. Nature 489, 359-361. doi: 10.1038/489359a

Haglund, E., Ndjeunga, J., Snook, L., and Pasternak, D. (2011). Dry land tree management for improved household livelihoods: farmer managed natural regeneration in Niger. J. Environ. Manag. 92, 1696-1705. doi: 10.1016/j. jenvman.2011.01.027

Holl, K. D., and Brancalion, P. H. S. (2020). Tree planting is not a simple solution. Science 368, 580-581. doi: 10.1126/science.aba8232

Holl, K. D., Crone, E. E., and Schultz, C. B. (2003). Landscape restoration: moving from generalities to methodologies. BioScience 53, 491-502. doi: 10.1641/00063568(2003)053[0491:lrmfgt]2.0.co;2

Hoosbeek, M. R., Remme, R. P., and Rusch, G. M. (2018). Trees enhance soil carbon sequestration and nutrient cycling in a silvopastoral system in south-western Nicaragua. Agroforest. Syst. 92, 263-273.

Hulvey, K. B., Leger, E. A., Porensky, L. M., Roche, L. M., Veblen, K. E., Fund, A., et al. (2017). Restoration islands: a tool for efficiently restoring dryland ecosystems? Restorat. Ecol. 25, S124-S134. doi: 10.1111/rec.12614

Jackson, N., Wallace, J., and Ong, C. (2000). Tree pruning as a means of controlling water use in an agroforestry system in Kenya. For. Ecol. Manag. 126, 133-148. doi: 10.1016/s0378-1127(99)00096-1

James, J. J., and Carrick, P. J. (2016). Toward quantitative dryland restoration models. Restorat. Ecol. 24, S85-S90. doi: 10.1111/rec.12393

Jose, S. (2009). Agroforestry for ecosystem services and environmental benefits: an overview. Agroforest. Syst. 76, 1-10. doi: 10.1007/978-90-481-3323-9_1

Komwihangilo, D., Goromela, E., and Bwire, J. (1995). Indigenous knowledge in utilization of local trees and shrubs for sustainable livestock production in central Tanzania. Livestock Res. Rural Dev. 6:15.

Krog, M., Theilade, I., Hansen, H. H., and Ruffo, C. (2005). Estimating usevalues and relative importance of trees to the Kaguru people in semi-arid Tanzania. For. Trees Livelihoods 15, 25-40. doi: 10.1080/14728028.2005.97 52505

Kuyah, S., Öborn, I., Jonsson, M., Dahlin, A. S., Barrios, E., Muthuri, C., et al. (2016). Trees in agricultural landscapes enhance provision of ecosystem services in Sub-Saharan Africa. Int. J. Biodivers. Sci. Ecosyst. Serv. Manag. 12, 255-273. doi: 10.1080/21513732.2016.1214178

Levis, C., Flores, B. M., Moreira, P. A., Luize, B. G., Alves, R. P., Franco-Moraes, J., et al. (2018). How people domesticated Amazonian forests. Front. Ecol. Evol. 5:171. doi: 10.3389/fevo.2017.00171

Lohbeck, M., Albers, A., Boels, L., Bongers, F., Morel, F., Sinclair, F., et al. (2020). Drivers of farmer-managed natural regeneration in the Sahel. Lessons for restoration. Sci. Rep. 10, 1-11. doi: 10.1038/s41598-020-70746-z 
Mayaya, H., Opata, G., and Kipkorir, E. (2015). Understanding climate change and manifestation of its driven impacts in the semi arid areas of Dodoma Region, Tanzania. Ethiopian J. Environ. Stud. Manag. 8, 364-376. doi: 10.4314/ejesm. v8i4.2

Minnemeyer, S., Laestadius, L., Sizer, N., Saint-Laurent, C., and Potapov, P. (2011). A World of Opportunity. Washington, DC: World Resource Institute.

Ndegwa, G., Iiyama, M., Anhuf, D., Nehren, U., and Schlüter, S. (2017). Tree establishment and management on farms in the drylands: evaluation of different systems adopted by small-scale farmers in Mutomo District, Kenya. Agroforest. Syst. 91, 1043-1055. doi: 10.1007/s10457-016-9979-y

Östberg, W. (2000). Eroded Consensus: Donors and Dilemmas of Degradation in Kondoa. Sweden: Nordiska afrikainstitutet.

Pimentel, D., and Burgess, M. (2013). Soil erosion threatens food production. Agriculture 3, 443-463. doi: 10.3390/agriculture3030443

R core team (2014). R: A Language and Environment for Statistical Computing. Vienna: R foundation for statistical computing.

Reed, J., van Vianen, J., Foli, S., Clendenning, J., Yang, K., MacDonald, M., et al. (2017). Trees for life: the ecosystem service contribution of trees to food production and livelihoods in the tropics. For. Policy Econ. 84, 62-71. doi: 10.1016/j.forpol.2017.01.012

Reij, C., and Garrity, D. (2016). Scaling up farmer-managed natural regeneration in Africa to restore degraded landscapes. Biotropica 48, 834-843. doi: 10.1111/ btp. 12390

Rinaudo, T. (2007). The development of farmer managed natural regeneration. Leisa Leusden 23:32.

Rinaudo, T., Muller, A., and Morris, M. (2018). FMNR Manual. Melbourne: World Vision Australia.

Roshetko, J. M., Lasco, R. D., and Angeles, M. S. D. (2007). Smallholder agroforestry systems for carbon storage. Mitig. Adapt. Strateg. Glob. Change 12, 219-242. doi: 10.1007/s11027-005-9010-9

Sabogal, C., Besacier, C., and McGuire, D. (2015). Forest and landscape restoration: concepts, approaches and challenges for implementation. Unasylva 66:3.

Scheid, A., Hafner, J., Hoffmann, H., Kächele, H., Sieber, S., and Rybak, C. (2018). Fuelwood scarcity and its adaptation measures: an assessment of coping strategies applied by small-scale farmers in Dodoma region, Tanzania. Environ. Res. Lett. 13:095004. doi: 10.1088/1748-9326/aadb27

Schroth, G., and Sinclair, F. L. (2003). Trees, Crops, and Soil Fertility: Concepts and Research Methods. Wallingford: CABI. doi: 10.1079/9780851995939.0000

Tedersoo, L., Laanisto, L., Rahimlou, S., Toussaint, A., Hallikma, T., and Pärtel, M. (2018). Global database of plants with root-symbiotic nitrogen fixation: nod DB. J. Veg. Sci. 29, 560-568. doi: 10.1111/jvs.12627

Timmer, L., Kessler, J., and Slingerland, M. (1996). Pruning of néré trees (Parkia biglobosa (Jacq.) Benth.) on the farmlands of Burkina Faso, West Africa. Agroforest. Syst. 33, 87-98. doi: 10.1007/bf00122891

Tougiani, A., Guero, C., and Rinaudo, T. (2009). Community mobilisation for improved livelihoods through tree crop management in Niger. GeoJournal 74:377. doi: 10.1007/s10708-008-9228-7

Webb, N. P., Marshall, N. A., Stringer, L. C., Reed, M. S., Chappell, A., and Herrick, J. E. (2017). Land degradation and climate change: building climate resilience in agriculture. Front. Ecol. Environ. 15, 450-459. doi: 10.1002/fee.1530

Weston, P., Hong, R., Kaboré, C., and Kull, C. A. (2015). Farmer-managed natural regeneration enhances rural livelihoods in dryland West Africa. Environ. Manag. 55, 1402-1417. doi: 10.1007/s00267-015-0469-1

Zomer, R. J., Neufeldt, H., Xu, J., Ahrends, A., Bossio, D., Trabucco, A., et al. (2016) Global tree cover and biomass carbon on agricultural land: the contribution of agroforestry to global and national carbon budgets. Sci. Rep. 6, 1-12. doi: 10.1007/978-3-319-92318-5_1

Conflict of Interest: The authors declare that the research was conducted in the absence of any commercial or financial relationships that could be construed as a potential conflict of interest.

Copyright (C) 2020 Moore, van Dijk, Asenga, Bongers, Sambalino, Veenendaal and Lohbeck. This is an open-access article distributed under the terms of the Creative Commons Attribution License (CC BY). The use, distribution or reproduction in other forums is permitted, provided the original author(s) and the copyright owner(s) are credited and that the original publication in this journal is cited, in accordance with accepted academic practice. No use, distribution or reproduction is permitted which does not comply with these terms. 